\title{
Determinants of an Effective Solid Wastes Collection at the Workplace: the Experience of the Council for Scientific and Industrial Research- Institute of Industrial Research, Accra, Ghana
}

\author{
Boniface Y. Antwi ${ }^{\mathrm{a}, *}$, Joyce Koranteng ${ }^{\mathrm{b}}$, Samuel Odei ${ }^{\mathrm{c}}$, Evelyn Anabila ${ }^{\mathrm{d}}$ \\ a, b, c, d Council for Scientific and Industrial Research-Institute of Industrial Research (CSIR-IIR), Materials and Manufacturing \\ Division, P.O. Box LG 576, Legon - Accra, Ghana
}

\section{Authors' Contributions}

This work was carried out in collaboration between authors. B. Y. Antwi: conceptualization of the study and experiment design. S. Odei, E. Anabila, J. Koranteng \& B. Y. Antwi: data collection. J. Koranteng \& B. Y. Antwi: manuscript preparation. Revision of the manuscript as well as corrections were made and approved by all authors.

\section{ARTICLE INFO}

\section{Article history:}

Received 15 October 2020

Received in revised form 29 October 2020

Accepted 29 October 2020

Available online

30 October 2020

Keywords:

Implementation indicators Solid wastes

Source separation

Sustainable environment

Workplace waste management

\begin{abstract}
The inefficient collection of solid wastes is a global phenomenon that has received attention in recent years for the ever-increasing annual waste generation records. However, indicators to the effective application of the amassing routs are missing. Hence, the generally accepted source-sorting model was explored to identify the determinants that will enhance source separation of wastes at the workplace. This paper presents a foremost report on the indicators to an effective operation of solid wastes source segregation. A quantitatively examined data was collected in sixty-six working days during a monitoring and evaluation process of twenty sets of twindustbins that were located at the study area. The generated solid wastes were commonly sorted $(65 \%)$ in comparison with the mixed collection. Most of the wastes were separated on the third month $(80 \%)$ of education compared to the first $(54 \%)$ and second months $(61 \%)$. Wednesday displayed the working day with the utmost sorted wastes $(73 \%)$ compared to the other days. All dustbins recorded impressive sorting at the different locations in the Institute. A little over one thousand Ghana cedis savings was made in the first year. Tested null hypothesis showed that, duration and timing of continuous education were significant determinants of the efficient source segregation, relative to the dustbin locations. Therefore, the daily education of waste generators on how to separate wastes at source and the economic benefits will enhance source separation irrespective of the location.
\end{abstract}

https://doi.org/10.37121/ijesr.v1.135

\section{Introduction}

The management of wastes has been a global concern since the 1960s when the world became aware of the impact on the environment and life [1]-[3]. The effective management of generated wastes has been benchmarked on three determinants, being the environmental sustainability, economic value and social implications [4]. Other indicators of a successful waste management practice are the energy consumption, landfill volume, waste generation, rate of composting, recycling and incineration [4]. However, the

\footnotetext{
* Corresponding author

E-mail address: boniface.antwi@gmail.com
}

2756-6773 / (C) 2020 the authors. Published by Sciengtex. This is an open access article under CC BY-NC-ND license (http://creativecommons.org/licenses/by-nc-nd/4.0/) 
required conditions to an effective implementation of a solid waste management practice such as the source sorting have not yet been explored.

The emphasis on domestic wastes generation and its management have received enormous attention in developing economies [5]-[11]. Nonetheless, the workplace experience is rarely discussed even though the working population keeps increasing. For this reason, it is imperative that, wastes management at the place of work is streamlined to protect the worker and the environment. Developed worlds like Europe [12] and America [13] have extensively studied [14] and adopted efficient systems [14], [15] of managing wastes whilst the story remains different in Africa [10], [16]-[19]. The proper collection of the wastes promotes a cleaner environment, low cost of recycling and healthy employees [20], [21].

Furthermore, the protection of the environment from solid wastes pollutants for economic gains enhances the sustainability of the collection process [22]. This is predominantly carried out by the source sorting of generated solid wastes for recycling, reuse, incineration, production of refuse derived fuels, and energy generation [23]-[25]. Additionally, the optimisation of this collection process is found in the use of two dustbin categories (food wastes and other wastes) over others [26], which contributes to the low cost of the implementation as well as, eliminate barriers [27] to the collection process. The reward and introduction of small recycling enterprises model [22] was also found to improve the segregation at source even though it did not guarantee sustainability. Similarly, the introduction of source separation at the workplace was found to enhance domestic segregation programme in Bangkok which indicates a direct correlation between workplace segregation and that of the household [28]. For this reason, a knowledge of the indicators to the effective implementation of source segregation at the workplace will correspondingly provide a bedrock for the domestic counterpart. In the source separation practice, the generators separated solid wastes before dumping in designated dustbins. The wastes were sorted according to the types [26]. For instance, in organic wastes dominated settlements, dustbins were labelled organic and non-organic wastes with different dustbin colour codes. Similarly, a plastic wastes dominated environment had dustbins for plastic and non-plastic wastes, and so on [26].

Relating the developed economies to that of the developing world, the source sorting of solid wastes have been efficiently implemented in countries like China, USA, and UK [29]. Ghana is yet to adopt the source segregation method of managing solid wastes on a large scale even though Institutional pilot programmes are sited, such as, the Environmental Protection Agency (EPA), the Ghana Armed Forces (GAF), and selected schools in Accra [30]. Likewise, the Council for Scientific and Industrial ResearchInstitute of Industrial Research (CSIR-IIR) introduced the piloting of source separation of solid wastes on its premises to improve the waste collection process.

\section{Methodology}

\subsection{Purpose of Study}

This study explored the CSIR-IIR pilot in the identification of the factors for the implementation of source sorting and collection of solid wastes at the workplace. Tested hypothesis $(\mathrm{H})$ included $\mathrm{H} 1$ to $\mathrm{H} 3$ stated as follow:

H1 - Continuous informal user education improves solid wastes separation at source.

H2 - Day of waste generation in the week (Monday to Friday) affects source sorting.

H3 - Dustbin location influences compliance to source sorting of solid wastes.

Considerations for the indicators have been sparingly mentioned in literature [28]. However, the records on the influence of the indicators on source segregation at the workplace are missing. Therefore, the work seeks to report findings from the study on the indicators for effective implementation of source segregation at the workplace.

\subsection{Research Questions}

The following questions directed the study:

(a) Does the duration of continuous informal education contribute to effective source separation?

(b) Does the day of waste generation influence the effectiveness of source sorting?

(c) Does the location of dustbin affects the efficient source separation?

The study area was the CSIR-IIR, East-Legon, Accra. The diverse social background of the staff provided bases for choosing the Institute. Data generated from the survey represent the varied social spectrum at the CSIR-IIR. 


\subsection{Study Design}

The exploratory research design was adopted, which was carried out by a quantitative data collection method. Administered questionnaires tallied generated graphs for interpretations.

\subsection{Study Area}

The CSIR-IIR offices are located at the commercial hub of East-Legon, a town in the Greater Accra region of Ghana (Fig. 1). The Institute is Ghana's leading industrial research institution formed through a merger of the former Industrial Research Institute (IRI) and Scientific Instrumentation Centre (SIC) in 1998. The CSIR-IIR drives national development and global competitiveness in industry through scientific and technological research. It is equipped with expertise in the physical sciences such as, Renewable energy and Energy audit, Industrial process design, Metrology, Information management, Materials and manufacturing processes, and Engineering design and prototyping. In 2018, the Institute received the best energy efficient organisation in Ghana award at the Ghana energy awards ceremony. It has a population size of 110 workers comprising of senior members (32), senior staff (59) and junior staff (19).

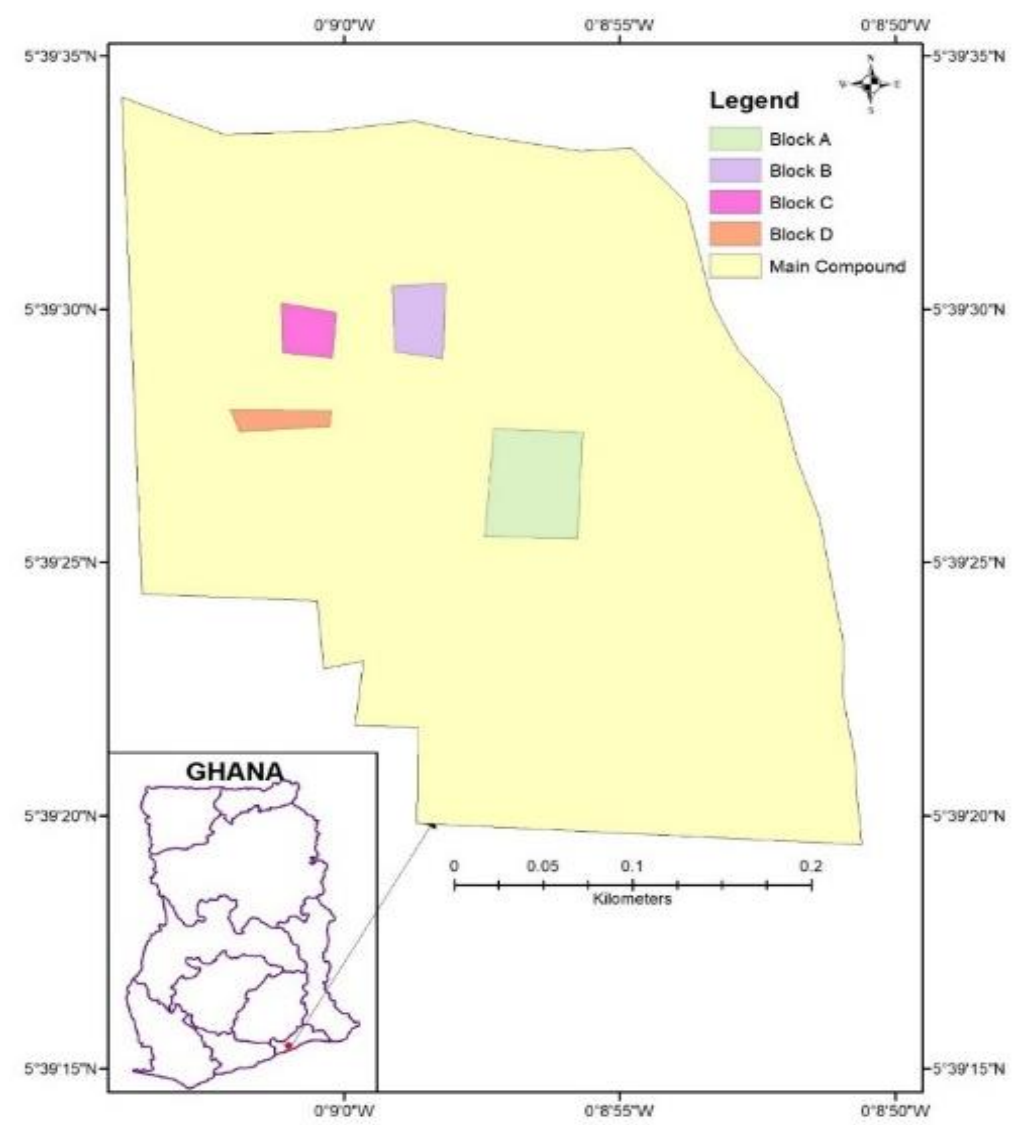

Fig. 1 A map of the CSIR-IIR compound showing dustbin location in the blocks

\subsection{Sampling and Sample Size}

Stratified sampling aided the data collection process. Sample size was calculated from the formula described by Yamane, 1973 as cited in [31], Eq. (1). The formula combined the number of available dustbins and the margin of error to arrive at a potential minimum number of dustbins for sampling.

$$
n=\frac{N}{1+N(\varepsilon)^{2}}=\frac{40}{1+40(0.10)^{2}}=29
$$

Given that: $n$ is the minimum sample size; $N$ is the total number of dustbins $(=40)$; and $\varepsilon$ is the margin of error $(10 \%)$. Hence, the 29 dustbins formed the minimum sample size. Nonetheless, the sampling covered the total number of available dustbins, 40 dustbins.

\subsection{Data Collection and Analysis}

The study period covered 66 working days during which a daily monitoring of the forty dustbins and logging of a table formed the collected data. The bins were colour coded bluish for plastic wastes and greenish for non-plastic wastes and located on the four blocks and the compound of the Institution, Fig. 1. Each dustbin was designated a number code comprising of the sampling year, the location, and the dustbin 
number. An early morning logging before working hours provided an opportunity to obtain dustbin status of the preceding day prior to the generation of fresh solid wastes on the day of sampling. The partly and not sorted waste bins had a manual handpicking to distinct the days of waste generation.

\subsection{The Instrument}

The instrument categorised the wastes sorting at the dustbins into 'not sorted', 'partly sorted', and 'sorted' ratings. A 'sorted' dustbin contained only the designated content. It did not have any foreign material in it. For instance, a dustbin for plastic wastes had only plastic wastes content and not mixed with non-plastic wastes, and vice versa. A setup with one mixed wastes dustbin and a well-sorted dustbin describes a 'partly sorted' bin. Similarly, a setup that had both dustbins with mixed contents formed the 'not sorted' bins. Dustbins that had no waste contents during the data collection were marked as "Empty". The carting personnel emptied the dustbins on Mondays and Wednesdays in differently colour-coded sacks for easy identification of the sorted wastes. Informal door-to-door interactions explained the sorting process and the relevance to staff of the Institute.

\subsection{Data Analyses}

A manual compilation of data using Microsoft Excel exported output onto the Statistical Package for the Social Sciences (SPSS) version 18 platform. Generated tables recorded the frequencies and calculated percentages under the three main research questions. The considered factors were dustbin location, day of waste generation in the week, and duration of continuous education. The location measured the effects of varied user background like the population size, age, expertise and other variables on the responses to sorting at source in a given area. The monthly assessment determined the changes in compliance level with duration of informal education. Day of waste generation in the week (Monday to Friday) identified the effect of the weekday on source segregation at the workplace.

\subsection{Calculation of Savings on the Wastes Collection}

The calculation of the savings followed Eq. (2).

$$
\text { Savings }=y(x-z)
$$

Where, $x$ is the cost of carting mixed wastes, $z$ is the cost of source separation, and $y$ is the period in months.

\section{Results and Discussion}

The general observation was that, generated solid wastes were sorted at source $(65 \%)$ and collected in all the dustbins (Fig. 2). This indicates a consumer endorsement of the source sorting and collection of solid wastes in dedicated dustbins.

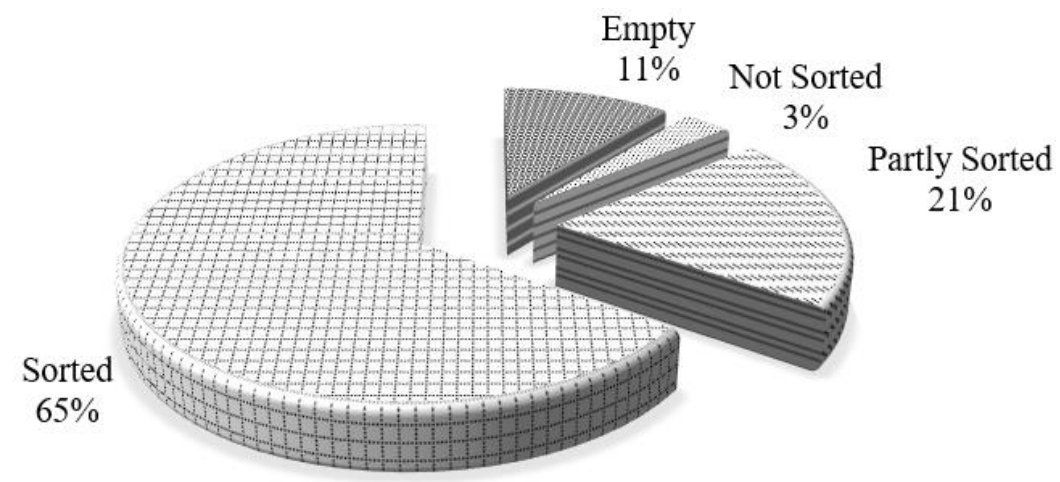

Fig. 2 A chart showing the general level of compliance by blocks

\subsection{Does the duration of continuous informal education contributes to effective source separation?}

The education of dustbin users is relevant to the effective implementation of a waste management practice [32], which was demonstrated by dustbin users in Naples and Palermo, Italy, for impressive collection of paper and cardboard wastes [32]. Furthermore, the work explores the duration of an informal enlightenment of respondents and its impact on source sorting. 


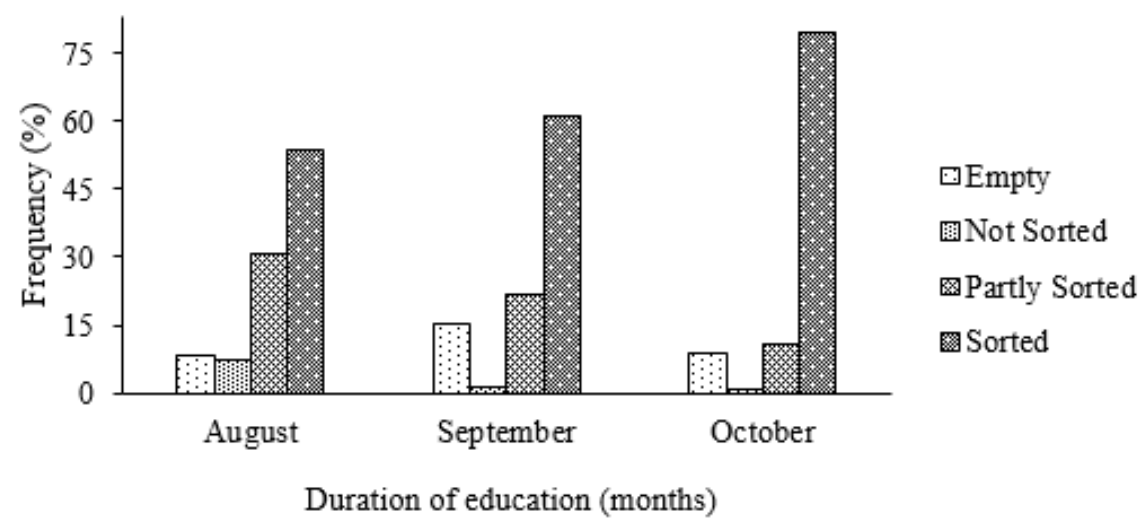

Fig. 3 Impact of informal education duration on source sorting and collection of solid wastes

The education of dustbin users was assessed to determine the influence on an efficient implementation of source sorting. An informal education was carried out to explain the source separation method and its benefits to the Institution. This was consistently carried out in the study period and compared to the changes in the sorting at the dustbins (Fig. 3). The source sorting improved with continuous education from August to October. A remarkable source sorting of the solid wastes was observed in the third month $(79.5 \%)$, which was an improvement over, the September - 61.3\% and August - 53.5\% records. Correspondingly, the first month (August) of education recorded the highest percentage of partly 'sorted' and 'not sorted' bins compared to the second (September) and third (October) months. Similarly, the increase in sorting induced a decline in the 'not sorted' and 'partly sorted' during the study period. Hence, it can be inferred that, source separation of solid wastes improved over a continuous period of informal education of dustbin users.

Furthermore, a test of the null hypothesis indicated a relationship between the source sorting and the period of informal education, Table 1 . The p-value $(0.00<0.05)$ demonstrated a significant level of $95 \%$ for the dependence of the source sorting on duration of dustbin user education. A longer period of education was required for the efficient source separation and collection of the wastes at the workplace.

Therefore, a successful implementation of source sorting will be dependent on a prolonged education of dustbin users, which was recommended in literature [26], [33], [34].

Table 1 Tests of the null hypotheses using the Pearson Chi-Square test

\begin{tabular}{lcccc}
\hline & & \multicolumn{3}{c}{ Indicators } \\
& & $\begin{array}{c}\text { Duration of } \\
\text { Education }\end{array}$ & $\begin{array}{c}\text { Working Day of the Week } \\
\text { (Monday to Friday) }\end{array}$ & Location of dustbin \\
\hline \multirow{3}{*}{ Pearson Chi-Square } & Value & 114.789 & 91.087 & 17.906 \\
& df & 6.000 & 12.000 & 12.000 \\
& Asymptotic sig. & 0.000 & 0.000 & 0.119 \\
\hline
\end{tabular}

\subsection{Does the day of waste generation influence the effectiveness of source sorting?}

The days of the week were explored in the determination of the factors that influenced efficient source segregation and collection of solid wastes. Source sorting of the solid wastes at the dustbins exhibited higher percentage frequencies than the partly sorted, not sorted and empty dustbins in the week. This indicates that the wastes were generally sorted in the days of the week, Fig. 4.

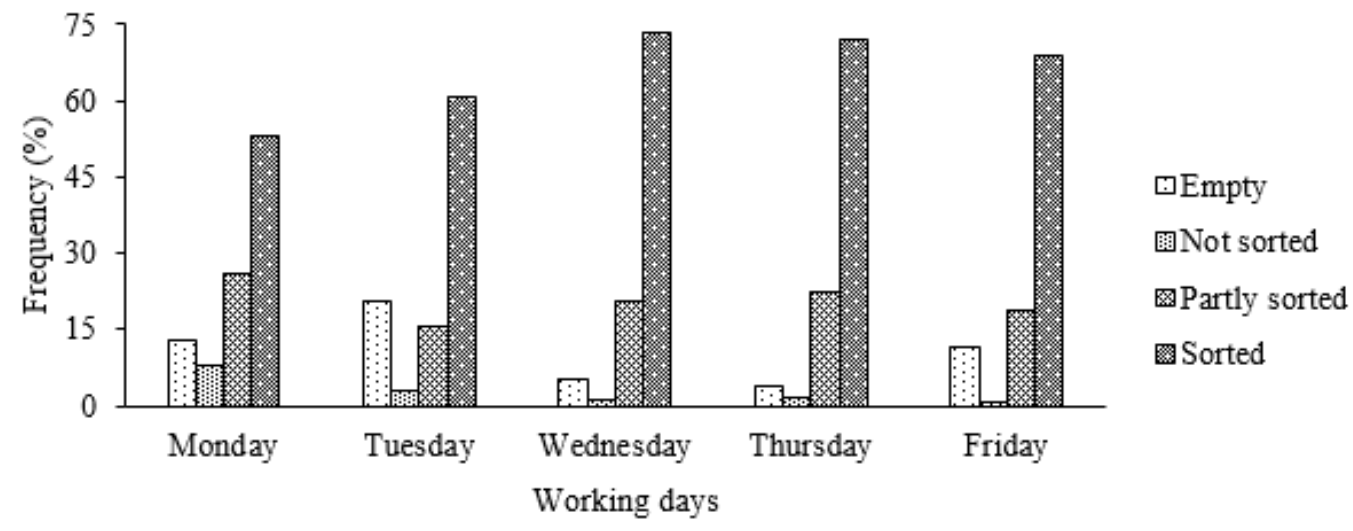

Fig. 4 A figure showing the sorting in the working days of the week 
However, the level of sorting did not show a logical trend from Monday to Friday. Wednesday displayed impressive source sorting (73.4 \%) compared to the other days. Monday exhibited the worst performing day for source segregation $(53.1 \%)$ which was attributed to the difficulty in readjusting to the waste disposal method of the Institute, which was different from the domestic mixed method. There was a gentle increase in the sorting from Monday to Wednesday and subsequently decline from Thursday to Friday. An indication of fatigue and changes in the behaviour of dustbin users [35], [36]. A test of the null hypothesis showed that, there was a relationship between the days of the week and effective source sorting, Table 1 .

\subsection{Does the location of dustbin affects the efficient source separation?}

The efficiency of the source segregation of solid wastes was assessed according to the five locations, being, blocks A, B, C, D and the compound.

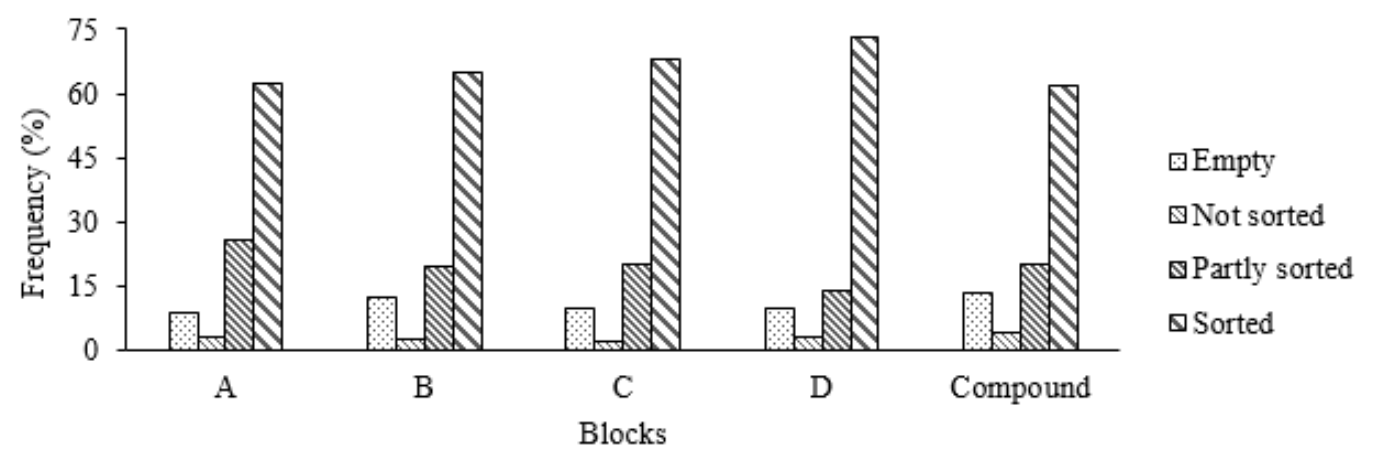

Fig. 5 Influence of dustbin location on source separation of wastes

All the blocks and the compound had higher percentages of source sorting and collection of the generated wastes in the twin-dustbins, Fig. 5. Block D displayed the highest compliance with $73 \%$ sorting compared to the other blocks. This was followed by blocks C (67.9\%), B (65.1\%), A (62.2\%), and the compound $(61.8 \%)$. A few of the dustbins were not sorted in the blocks compared to those on the compound. This can be attributed to the wastes that were generated by visitors to the Institute who were mostly not educated on source sorting of solid wastes.

The null hypothesis which states that, dustbin location does not influence the effectiveness of solid wastes collection was tested by the Pearson Chi-square test, Table 1 . The p-value $(0.119>0.05)$ indicates no relationship between the effective waste collection, and the location of the dustbins. There was no significant difference in the location of the dustbins and the effectiveness of the source sorting and collection. The numerical differences observed in Fig. 5 was not significant in the test. Hence, the effectiveness of source separation at the Institute was independent of the dustbin location which is consistent with literature [37]-[39].

\subsection{Economic Benefits}

The sustainability of the waste collecting system was not only dependent on the environmental and social impact but the economics of the implementation process as well [40]. The financial gains in managing the solid wastes improved waste collection in the literature [22], [33], [41], [42], which indicates that, in the absence of money incentive schemes, [22] source segregation will fail. However, a comparison of the carting cost for sorted wastes which in most cases was null to the mixed wastes demonstrated an indirect financial gain, Fig. 6.

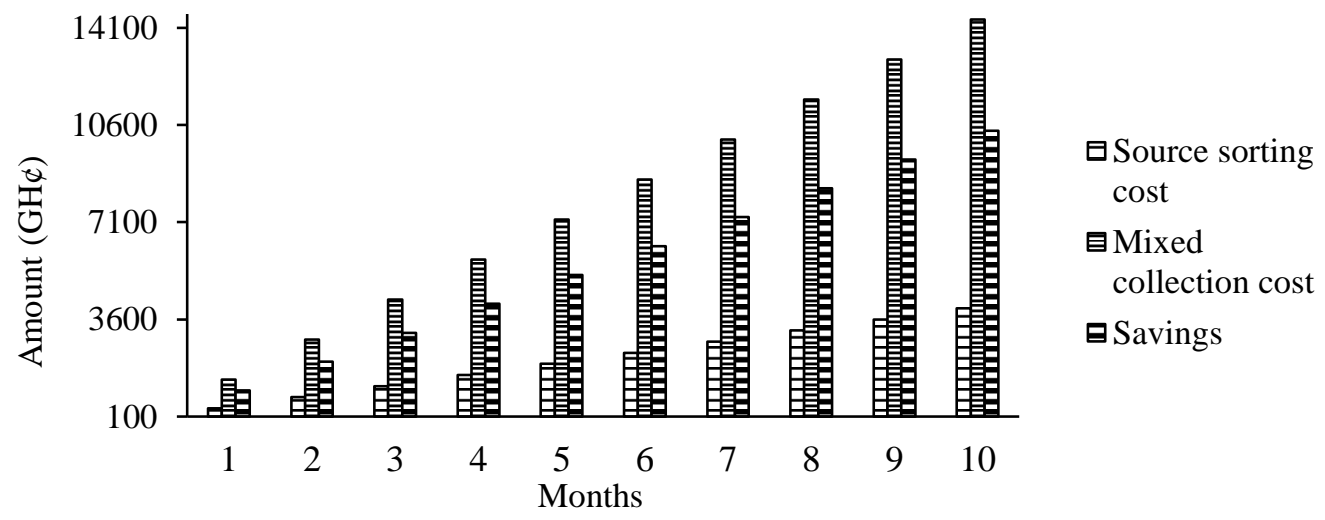

Fig. 6 Financial gains by the Institute 
The Institute made savings on the disposal of the sorted wastes compared to the mixed ones. The sorted waste became a resource, and freely collected by organic composting and biogas generation firms, as well as recycling companies. And so, the source sorting eliminated the cost of incentive schemes by governments whilst dustbin users made gains from the savings on the carting of their wastes.

The non-plastic wastes which were mainly food and other organic wastes were fed into a bio-digester system for the generation of methane gas whilst the clean plastics were sent to industry for recycling. The unrecyclable wastes were subsequently incinerated into ashes. A little over one thousand Ghana cedis was saved in a year of the implementation. A projection indicates a yield of ten thousand Ghana cedis in ten years at the same rate of waste carting and cost of implementation. Hence, the dustbin users and management made economic gains in the implementation process which enhanced the sustainability [43].

\section{Conclusion}

Altogether, the determinants to an efficient source sorting were found to lie in the duration and timing of educating dustbin users at the workplace. The economic benefits of the waste management method was also relevant in ensuring its sustainability. Location of dustbins was on the other hand not significant to the implementation of the source sorting process. Hence, a successful replacement of mixed waste collection with source segregation requires a medium to long-term informal education of dustbin users, which should be intensified on the first and fourth days of implementation. The economic gains in putting-in-place the source separation system provides a bedrock for the sustainability of the waste management practice [44].

\section{Conflict of Interests}

The authors declare that there is no conflict of interests regarding the publication of this paper.

\section{Acknowledgements}

The authors thank Dr. William Oduro, Mr. Kissiedu Akufo-Kumi and Dr. Francis Boateng Agyenim for the administrative support during data collection.

\section{ORCID}

B. Y. Antwi (D) https://orcid.org/0000-0002-7016-345X

\section{References}

[1] L. R. David C. Wilson, Prasad Modak, Reka Soos, Ainhoa Carpintero Rogero, Costas Velis, Mona Iyer, Otto Simonett, "Global waste management outlook," United Nations Environment Programme DTI /1957/JA, 2015.

[2] N. Ferronato and V. Torretta, "Waste Mismanagement in Developing Countries: A Review of Global Issues," International Journal of Environmental Research and Public Health, vol. 16, pp. 1060, 2019.

[3] L. Rushton, "Health hazards and waste management," British Medical Bulletin, vol. 68, pp. 183-197, 2003.

[4] R. M. Deus, Bezerra, B.S. \& Battistelle, R.A.G., "Solid waste indicators and their implications for management practice," International Journal of Environmental Science \& Technology, vol. 16, pp. 1129, 2019.

[5] R. M. Yoada, D. Chirawurah, and P. B. Adongo, "Domestic waste disposal practice and perceptions of private sector waste management in urban Accra," BMC public health, vol. 14, pp. 697-705, 2014.

[6] Z. Han, Z. Dan, G. Shi, L. Shen, W. Xu, and Y. Xie, "Characteristics and management of domestic waste in a rural area of the Tibetan Plateau," Journal of the Air \& Waste Management Association, vol. 65, pp. 1365-1375, 2015/11/02 2015.

[7] S. J. Mandevere B, "Household solid waste management: how effective are the strategies used in Harare Zimbabwe?," Journal of Environmental Waste Management and Recycling, vol. 1, pp. 16-22, 2018.

[8] J. Asante, "Assessment of household solid waste management practices in the Sunyani West district," MPH, College of Health Sciences, School of Public Health, University of Ghana, 2016.

[9] R. K. Rai, M. Nepal, M. S. Khadayat, and B. Bhardwaj, "Improving municipal solid waste collection services in developing countries: a case of Bharatpur metropolitan city, Nepal," Sustainability, vol. 11, pp. 3010, 2019.

[10] N. Yukalang, B. Clarke, and K. Ross, "Solid waste management solutions for a rapidly urbanizing area in Thailand: recommendations based on stakeholder input," International Journal of Environmental Research and Public Health, vol. 15, pp. 1302, 2018.

[11] N. Ferronato, M. A. Gorritty Portillo, E. G. Guisbert Lizarazu, V. Torretta, M. Bezzi, and M. Ragazzi, "The municipal solid waste management of La Paz (Bolivia): challenges and opportunities for a sustainable development," Waste Management \& Research, vol. 36, pp. 288-299, 2018.

[12] L. Traven, I. Kegalj, and I. Šebelja, "Management of municipal solid waste in Croatia: analysis of current practices with performance benchmarking against other European Union member states," Waste Management \& Research, vol. 36, pp. 663-669, 2018.

[13] R. A. Arnott, "Waste management in northern Europe," Waste Management \& Research, vol. 3, pp. 289-302, 1985.

[14] M. A. Nwachukwu, M. Ronald, and H. Feng, "Global capacity, potentials and trends of solid waste research and management," Waste Management \& Research, vol. 35, pp. 923-934, 2017. 
[15] A. Pires, G. Martinho, and N.-B. Chang, "Solid waste management in European countries: a review of systems analysis techniques," Journal of Environmental Management, vol. 92, pp. 1033-1050, 2011.

[16] A. Oke, "Workplace waste recycling behaviour: a meta-analytical review," Sustainability, vol. 7, pp. 7175-7194, 2015.

[17] P. R. O'Leary, P. W. Walsh, and R. K. Ham, "Managing solid waste," Scientific American, vol. 259, pp. 36-45, 1988.

[18] E. H. Ezechi, C. G. Nwabuko, O. C. Enyinnaya, and C. J. Babington, "Municipal solid waste management in Aba, Nigeria: challenges and prospects," Environmental Engineering Research, vol. 22, pp. 231-236, 2017.

[19] D. Mmereki, "Current status of waste management in Botswana: a mini-review," Waste Management \& Research, vol. 36 , pp. 555-576, 2018.

[20] H. I. Abdel-Shafy and M. S. M. Mansour, "Solid waste issue: Sources, composition, disposal, recycling, and valorization," Egyptian Journal of Petroleum, vol. 27, pp. 1275-1290, 2018.

[21] M. C. Assis, V. A. P. Gomes, W. C. Balista, and R. R. D. Freitas, "Use of performance indicators to assess the solid waste management of health services," Proceedings of the Brazilian Academy of Sciences, vol. 89, pp. 2445-2460, 2017.

[22] W. Xu, C. Zhou, Y. Lan, J. Jin, and A. Cao, "An incentive-based source separation model for sustainable municipal solid waste management in China," Waste Management \& Research, vol. 33, pp. 469-476, 2015.

[23] R. G. d. S. M. Alfaia, A. M. Costa, and J. C. Campos, "Municipal solid waste in Brazil: a review," Waste Management \& Research, vol. 35, pp. 1195-1209, 2017.

[24] S. P. Gundupalli, S. Hait, and A. Thakur, "A review on automated sorting of source-separated municipal solid waste for recycling," Waste Management, vol. 60, pp. 56-74, 2017.

[25] Å. Davidsson, C. Gruvberger, T. H. Christensen, T. L. Hansen, and J. I. C. Jansen, "Methane yield in source-sorted organic fraction of municipal solid waste," Waste Management, vol. 27, pp. 406-414, 2007.

[26] H. Chen, Y. Yang, W. Jiang, M. Song, Y. Wang, and T. Xiang, "Source separation of municipal solid waste: the effects of different separation methods and citizens' inclination - case study of Changsha, China," Journal of the Air \& Waste Management Association, vol. 67, pp. 182-195, 2017.

[27] T. Babazadeh, H. Nadrian, M. Mosaferi, and H. Allahverdipour, "Identifying challenges and barriers to participating in the source separation of waste program in Tabriz, Northwest of Iran: a qualitative study from the citizens' perspective," Resources, vol. 7, p. 53, 2018.

[28] S. Vassanadumrongdee and S. Kittipongvises, "Factors influencing source separation intention and willingness to pay for improving waste management in Bangkok, Thailand," Sustainable Environment Research, vol. 28, pp. 90-99, 2018.

[29] J. Ma, K. W. Hipel, M. L. Hanson, X. Cai, and Y. Liu, "An analysis of influencing factors on municipal solid waste source-separated collection behaviour in Guilin, China by using the theory of planned behaviour," Sustainable Cities and Society, vol. 37, pp. 336-343, 2018.

[30] G. D. Zaney, Implementation of source waste segregation programme begins, 2017, Available: http://www.ghana.gov.gh/index.php/media-center/news/3702-implementation-of-source-waste-segregationprogramme-begins (accessed: 10/09/2019).

[31] S. Ajay, and B. Micah, "Sampling techniques and determination of sample size in applied statistics research: an overview," International Journal of Economics, Commerce and Management, vol. 2, no. 11, pp. 1-22, 2014

[32] G. De Feo, C. Ferrara, V. Iannone, and P. Parente, "Improving the efficacy of municipal solid waste collection with a communicative approach based on easily understandable indicators," Science of The Total Environment, vol. 651, pp. 2380-2390, 2019.

[33] S. Oduro-Kwarteng, "Source separation and recycling potential of municipal solid waste in Ghana," Management of Environmental Quality: An International Journal, vol. 27, pp. 210-226, 2016.

[34] N. Parvez, A. Agrawal, and A. Kumar, "Solid waste management on a campus in a developing country: a study of the Indian Institute of Technology Roorkee," Recycling, vol. 4, pp. 28, 2019.

[35] H. Zhang and Z.-G. Wen, "Residents' household solid waste source separation activity: a case study of Suzhou, China," Sustainability, vol. 6, pp. 6446-6466, 2014.

[36] T. T. P. Nguyen, D. Zhu, and N. P. Le, "Factors influencing waste separation intention of residential households in a developing country: evidence from Hanoi, Vietnam," Habitat International, vol. 48, pp. 169-176, 2015.

[37] K. Miezah, K. Obiri-Danso, Z. Kádár, B. Fei-Baffoe, and M. Y. Mensah, "Municipal solid waste characterisation and quantification as a measure towards effective waste management in Ghana," Waste Management, vol. 46, pp. 15-27, 2015.

[38] D. Purkayastha, M. Majumder, and S. Chakrabarti, "Collection and recycle bin location-allocation problem in solid waste management: a review," Pollution, vol. 1, pp. 175-191, 2015.

[39] S. P. S. Pradeep Rathore, Arti Singh, "Location-allocation of bins in urban solid waste management: a case study of Bilaspur city, India," Environment, Development and Sustainability, pp. 1-23, 2019.

[40] H. Hettiarachchi, J. N. Meegoda, and S. Ryu, "Organic waste buyback as a viable method to enhance sustainable municipal solid waste management in developing countries," International Journal of Environmental Research and Public Health, vol. 15, pp. 2483, 2018.

[41] G. De Feo, C. Ferrara, A. Finelli, and A. Grosso, "Environmental and economic benefits of the recovery of materials in a municipal solid waste management system," Environmental Technology, vol. 40, pp. 903-911, 2019.

[42] V. Owusu, E. Adjei-Addo, and C. Sundberg, "Do economic incentives affect attitudes to solid waste source separation? Evidence from Ghana," Resources, Conservation and Recycling, vol. 78, pp. 115-123, 2013.

[43] Z. Chu, W. Wang, B. Wang, and J. Zhuang, "Research on factors influencing municipal household solid waste separate collection: bayesian belief networks," Sustainability, vol. 8, pp. 152, 2016.

[44] R. Maletz, "Success factors for the implementation of separate collection systems," in Source Separation and Recycling: Implementation and Benefits for a Circular Economy, R. Maletz, C. Dornack, and L. Ziyang, Eds., Cham: Springer International Publishing, 2018, pp. 297-302. 